

\section{REVISTA \\ TEORÍA Y PRÁCTICA \\ DE LA \\ ARQUEOLOGÍA HISTÓRICA LATINOAMERICANA}

ISSN: 2250-866X (impreso) | ISSN: 2591-2801 (en línea)

AÑo VIII, VOLUMEN 8, PRIMAVERA DE 2019

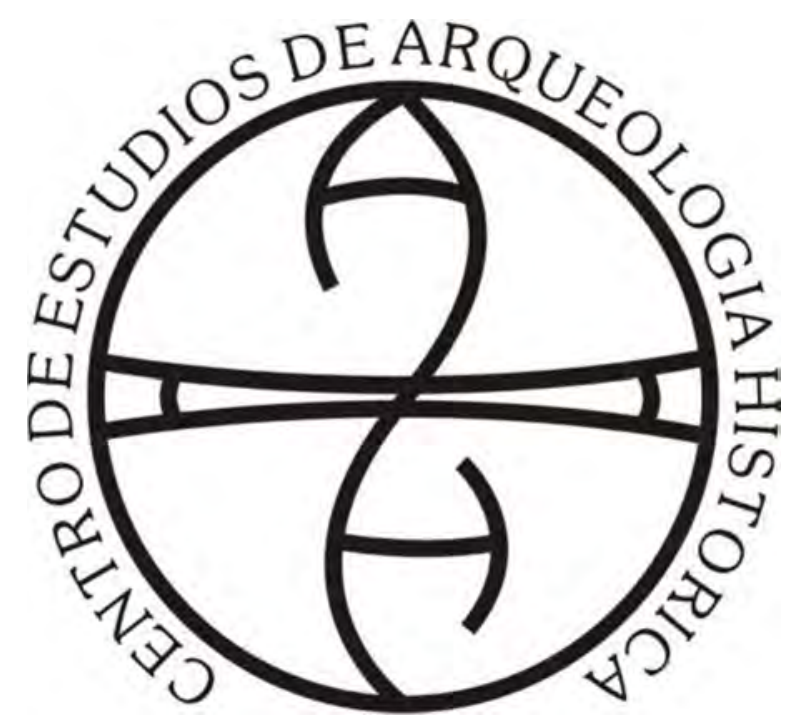

Centro de Estudios de Arqueología Histórica

FACULTAD DE HUMANIDADES Y ARTES | UNIVERSIDAD NACIONAL DE ROSARIO 
(Universidad Nacional de Rosario, Universidad Nacional de Río Cuarto,

Universidad Nacional de San Juan, Universidad de la República, Universidad Nacional de Trujillo)

\author{
AUTORIDADES DE LA UNIVERSIDAD NACIONAL DE ROSARIO \\ RECTOR: Lic. Franco Bartolacci \\ VICE-RECTOR: Od. Darío Macía \\ SECRETARIO GENERAL: Prof. José Goity \\ SECRETARIA ACADÉMICO Y DE APRENDIZAJE: Dr. Marcelo Vedrovnik \\ SECRETARÍA DE CIENCIA TECNOLOGÍA E INNOVACIÓN \\ PARA EL DESARROLLO: Ing. Guillermo Montero.
}

\author{
AUTORIDADES DE LA FACULTAD DE HUMANIDADES Y ARTES \\ DECANO: Prof. Alejandro Vila \\ VICEDECANA: Prof. Marta Varela \\ SECRETARIA ACADÉMICA: Dra. Marcela Coria
}

\author{
AUTORIDADES DEL CENTRO DE ARQUEOLOGÍA HISTÓRICA \\ DIRECTORA: Dra. Ana Rocchietti \\ SECRETARIA: Prof. Nélida de Grandis \\ PROSECRETARIA: Lic. Marianela Bizcaldi
}

DIRECTORAS - EDITORAS:

Dra. Ana Rocchietti y Prof. Nélida De Grandis

SECRETARIA DE EDICIÓN: Dra. Irene Dosztal

Este número es co-edición de las ponencias

del VIII Congreso Nacional de Arqueología Histórica (2018) entre:

Centro de Estudios en Arqueología Histórica: Directora Ana Rocchietti

Centro de Estudios en Arqueología Regional: Director Fernando Oliva

Centro de Estudios en Arqueología Subacuática: Directora Mónica Valentini

Departamento de Arqueología, Escuela de Antropología: Director Fernando Oliva
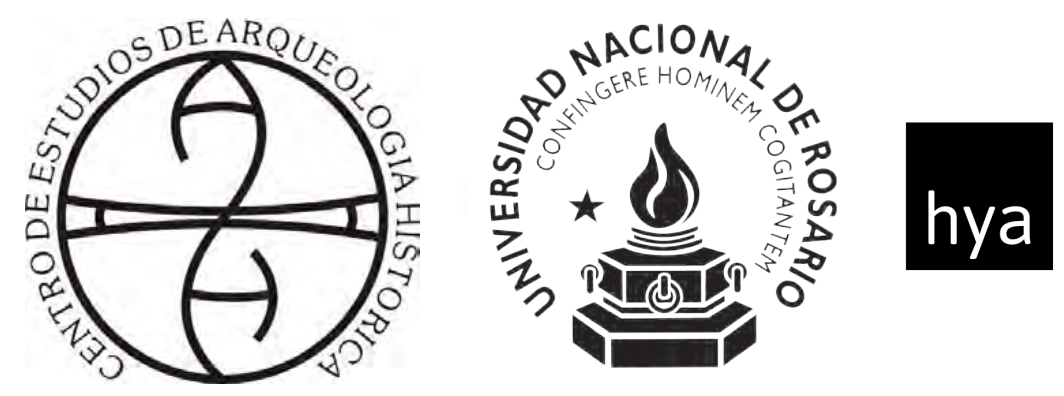

Facultad de Humanidades

y Artes_UNR
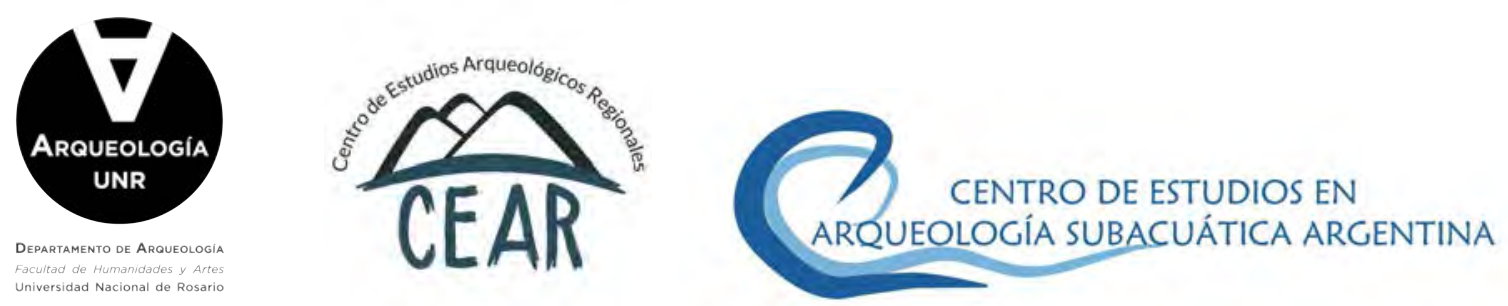
Comité Permanente de los Congresos Nacionales de Arqueología Histórica

Dr. Daniel Schávelzon (Universidad Nacional de

Buenos Aires)

Prof. María Teresa Carrara (Universidad Nacional de Rosario)

Prof. Carlos Baldassarre (Museo Municipal de Río

Grande, Tierra del Fuego) in memoriam

Dr. Mariano Ramos (Universidad Nacional de Luján, CONICET)

Dr. Horacio Chiavazza (Universidad Nacional de Cuyo)

Dra. Ana María Rocchietti (Universidad Nacional de

Rosario, Universidad Nacional de Río Cuarto)

Lic. Facundo Gómez Romero (Universidad Autónoma

de Barcelona)

\section{Comité Científico}

Dra. Tânia Andrade Lima (Universidade Federal do Rio de Janeiro)

Prof. Réginald Auger (CELAT/Département des

Sciences Historiques, Université Laval, Canadá)

Dr. Roberto Bárcena (Universidad Nacional de Cuyo, CONICET)

Dra. Marta Bonaudo (Universidad Nacional de Rosario, CONICET)

Dr. Leonel Cabrera (Universidad de la República, Uruguay)

Dr. Luis María Calvo (Universidad Católica de Santa

$\mathrm{Fe})$

Prof. Juan Castañeda Murga (Universidad Nacional de

Trujillo, Perú)

Dr. Carlos Ceruti (Museo de Ciencias Naturales y

Antropología "Prof. Antonio Serrano". Paraná)

Dr. Horacio Chiavazza (Universidad Nacional de Cuyo)

Dra. Silvia Cornero (Universidad Nacional de Rosario)

Prof. Pedro Paulo Funari (Universidade Estadual de

Campinas, Brasil)

Lic. Jorge A. Gamboa Velásquez (Universidad Nacional

Santiago Antuñez de Mayolo, Perú)

Dr. Eduardo Alejandro García (Universidad Nacional de

San Juan, CONICET)

Prof. Nélida De Grandis (Universidad Nacional de

Rosario)

Dr. Juan Bautista Leoni (Universidad Nacional de

Rosario, CONICET)

Dra. Amancay Martínez (Universidad Nacional de San

Luis)

Dra. Catalina Teresa Michieli (Universidad Nacional de

San Juan, CONICET)

Lic. Fernando Oliva (Universidad Nacional de Rosario)

Ing. Adrián Pifferetti (Universidad Tecnológica
Nacional Regional Rosario)

Dr. Mariano Ramos (Universidad Nacional de Luján, CONICET)

Dra. Ana María Rocchietti (Universidad Nacional de Rosario)

Dr. Daniel Schávelzon, (Universidad Nacional de Buenos

Aires, CONICET)

Dra. Carlota Sempé (Universidad Nacional de La Plata)

Dr. Mario Silveira (Universidad Nacional de Buenos Aires)

Dra. Silvia Simonassi (Universidad Nacional de Rosario)

Dra. Alicia Tapia (Universidad Nacional de Buenos Aires, Universidad Nacional de Luján)

Lic. Mónica P. Valentini (Universidad Nacional de Rosario)

Agrim. Benito Vicioso (Universidad Nacional de Rosario)

\section{Evaluaron este volumen}

Roberto Bárcena, María Teresa Boschin, Leonel Cabrera, Ulises Camino, María Rosa Carbonari, Carlos Ceruti, Horacio Chiavazza, Nicolás Ciarlo, Silvia Cornero, Eduardo Crivelli, Javier García Cano, Martín Gentinetta, María Laura Gili, Carlos Landa, Matilde Lanza, Melina Malandrino, Sebastián Pastor, Victoria Pedrotta, Josefina Piana,

Mercedes Podestá, Mariano Ramos, Daniel Schavelzon, Diana Tamburini, Mónica Therrien, Mónica Valentini y María Teresa Boschin

\section{Diseño y diagramación}

Eugenia Reboiro

(eugenia.reboiro@gmail.com)

\section{Curadoría}

Ana Rocchietti e Irene Dosztal

Foto de tapa: imagen del texto de Croce.

\section{Propietario responsable:}

Facultad de Humanidades y Artes, Universidad Nacional de Rosario Centro de Estudios de Arqueología Histórica

Entre Ríos 758. Rosario, provincia de Santa

Fe (2000). Argentina.

Telf.: +54 (0341) 4802670

E-mail: ceahunr@gmail.com

Decreto Ley 6422/57 de Publicaciones

Periódicas 


\section{Índice}

Editorial.

Arqueología histórica: programa de investigación y dimensiones epistemológicas...9 Ana María Rocchietti

De lozas, iglesias y machaqueños. Primeros pasos hacia una arqueología histórica en la cuenca norte del río desaguadero (La Paz, Bolivia).

Salvador Arano Romero

Identificación arqueológica de acciones militares en el campo de batalla de Cepeda, 1859.

Juan B. Leoni, Lucas H. Martínez, Cecilia Arias Morales, Daniela Cadenas,

Faustino Godoy, Mauro Ganem, María de la Paz Blanche y Héctor Meletta

Para una historia de la arqueología urbana en Buenos Aires (1848-1910) .59

Daniel Schávelzon y Francisco Girelli

Definiendo la cultura material colonial a partir de colecciones arqueológicas del Museo de La Plata.

Melina Bednarz, Julieta Penesis y Ana Igareta

La tangibilidad del conflicto: Arqueología del presente en las fronteras del norte santafesino....

Paula Del Río y Silvia Cornero

Arqueología histórica: evidencia material en el paisaje del establecimiento jesuita "La saladilla” (quebrada de Saladillo, La Rioja, Argentina). Juan Carlos Giuliano, Maira Ayelén Carrizo y María Soledad Gheggi

Graffiti ¿evidencia arqueológica o acto vandálico?. Camila Oliva

Arqueología histórica de los sistemas hidráulicos de la Hacienda

Jalpa de Cánovas, Guanajuato, México, y su relación con el sistema-mundo, Siglos XVIII-XIX

José Alberto Aguirre Anaya y Edgar Quispe Pastrana 
Paseo del bajo: una trinchera en la historia de Buenos Aires.................................143 Federico Martín Croce

Diferentes concepciones del patrimonio y su aplicación a la Casa Histórica de Tucumán también llamada Casa de la Independencia........................................155 Guillermo Etchevers

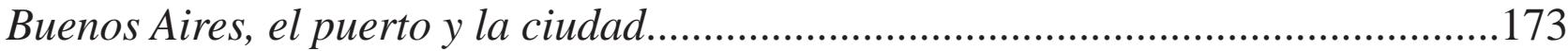
Mónica P. Valentini y Javier García Cano 


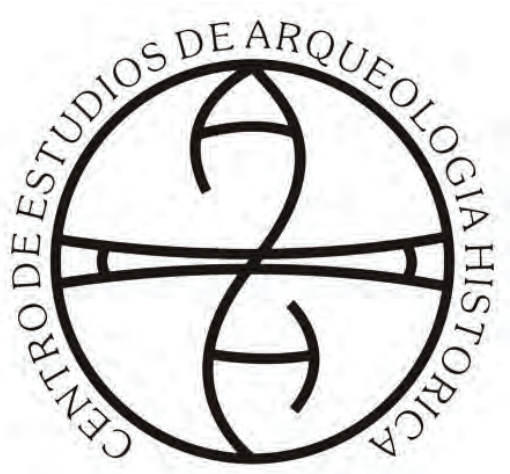

Centro de Estudios de Arqueología Histórica

Universidad Nacional de Rosario
Teoría y Práctica de la Arqueología Histórica

Latinoamericana | Año VIII. Vol. 8 | 2019

Revista del Centro de Estudios de Arqueología

Histórica, Facultad de Humanidades y Artes, Universidad Nacional de Rosario

https://teoriaypracticaah.unr.edu.ar/index.php/index ceahunr@gmail.com

ISSN en línea: 2591-2801

ISSN versión impresa: 2250-866X

\title{
BuenOS AIRES, EL PUERTO Y LA CIUDAD
}

\author{
Mónica P. Valentini* y Javier García Cano**
}

\section{Resumen}

La ciudad de Buenos Aires debe su existencia en gran medida a su relación con la costa y el medio acuático circundante. El puerto y la relación con el paisaje costero fueron, en un principio, los ejes importantes en el desarrollo de la urbe. Ese paisaje costero y los cambios producidos se pueden observar en imágenes de distintas épocas a través de las pinturas u obras de distintos artistas. Presentamos un análisis de algunas obras conocidas y ciertas ideas en relación a las imágenes y el paisaje en dónde se encontraron los restos del pecio de Zencity en Puerto Madero.

Palabras clave: Puerto, paisaje, costa, navegantes.

\begin{abstract}
Buenos Aires owes its existence largely to its relationship with the coast and surrounding waterways. The port and the relationship with the coastal landscape were, initially, the important issues in the development of the city. This coastal landscape and the changes can be seen in images from different eras through paintings or works of different artists. We present an analysis of some well-known works and certain ideas in relation to images and landscape where the remains of the wreck of Zencity Puerto Madero found.
\end{abstract}

Keywords: harbor, landscape, coast, sailors.

\section{Introducción}

La ribera de la ciudad de Buenos Aires, es casi hoy imposible de reconocer en el paisaje urbano actual. Fue sepultada por la urbanización y el equipamiento portuario moderno. Así arribamos al punto que sólo en excavaciones podemos reconocer los sedimentos y registros ambientales del antiguo entorno fluvial. Desde la conquista europea de América, los puertos fueron imprescindibles para la vida en las ciudades

* Universidad Nacional de Rosario.mopavalentini@gmail.com

** Universidad de Buenos Aires. jafegcano@gmail.com 
litorales. Desde el siglo XVI, pero especialmente desde finales del siglo XVIII, aparecen usos culturales del espacio que producen, importan, descartan y transforman el paisaje costero de la ciudad. La costa actual es el resultado de numerosas tareas de relleno artificial que dieron lugar a la progradación de la ribera desde el año 1836 (Marcomini y López 2004: 261) (2 $^{12}$

Puerto Madero no es un barrio como cualquier otro, su diseño fue pensado con un criterio diferente al del resto de los barrios. Desde un principio acaparó la absorción de inversiones tanto nacionales como extranjeras que lo convirtieron en un barrio exclusivo y con una intensa construcción urbana.

A través de los años y de la gran cantidad de emprendimientos inmobiliarios que no dejan de construirse en la zona es que se han realizado varios hallazgos arqueológicos de gran envergadura: en 1887 durante las excavaciones de Dársena Sur, se encontraron los restos de un casco de madera con restos de armas asociados, cuando en 1890 se realizaban tareas de remoción de tierra para la construcción del Dique 3 de Puerto Madero se descubrió el casco de una nave de madera de grandes dimensiones (Fernández, 1999). Durante los dragados de 1933 en la Dársena Norte, se recuperaron varios cañones, carronadas e implementos y parte de una quilla, un codaste y un timón, así como anclas y anclotes que podrían atribuirse a la fragata 25 de Mayo que se hundió junto a una nave mercante llamada Florida que hoy se encuentran en el Museo Naval de la Nación (Ciarlo, 2008). Entre estos hallazgos el último es el de los restos de una embarcación mercante española del siglo XVIII con parte de su carga a bordo, el pecio de Zencity (Valentini et al 2012 a).

Es a partir de éste último hallazgo que hemos puesto en funcionamiento una serie de ideas y reflexiones en relación al frente costero de la ciudad. La denominación de puerto cuando de acuerdo a distintas referencias solo encontramos en realidad un fondeadero cuando la relación de la ciudad con ese medio acuático que la circunda, fue en gran medida, la razón de su existencia.

No pretendemos que sea una narrativa extensa sino las primeras concepciones de pensamientos que nos han hecho reflexionar sobre un espacio o paisaje donde hemos encontrado un contexto arqueológico particular.

Reflexiones acerca de los factores y marcos de referencia que sin duda determinaron algunas características identitarias del territorio que, hacia el siglo XX, otorgaran un reconocimiento mundial de la ciudad de Buenos Aires de fuerte tono cosmopolita.

Buenos Aires es un nombre que plantea ciertas relaciones geográficas genéricas. No se refiere a un lugar, pero es un lugar. No implica una posición especial en el territorio, pero se restringe a ciertas opciones. Establece cierto parámetro de calidad, pero no define su escala.

No se repite como nombre en el resto del mundo para identificar ciudad alguna a la vera de un gigantesco estuario. El río al cual también se asocia el nombre de la ciudad, se denomina de una forma muy distinta y a la vez utiliza categorías muy distintas. Buenos Aires, Río de la Plata. Esto se mantiene aun usando los nombres completos. Ambos casos resultan de la actividad de navegantes que asignaron estos nombres de origen europeo a estos territorios americanos.

\section{Buenos Aires, el Río de la Plata, navíos y navegantes}

Parece razonable al recordar que la nominación de la ciudad resulta de la actividad fundacional ejercida por navegantes y en forma reiterada con una diferencia temporal de medio siglo. Tanto en 1536 como en 1580, la posición del asentamiento que terminaría siendo conocido bajo el nombre de Buenos Aires fue decisión de quienes desarrollaron un conocimiento de esta geografía desde el agua, desde las naves en las que arribaron. 
Cabe mencionar que la forma de aproximación a estos territorios que tuvieron estos europeos del SXVI fue navegando una enorme superficie de agua dulce del estuario del Río de La Plata. Navegaron desde la boca del estuario (sin la posibilidad de avistar riberas) hacia las nacientes del mismo, río arriba. En ese punto, después de pensar que navegaban un "Mar Dulce” (primer nombre asignado al río) vieron bordes costeros, y en especial relevaron la banda Sur-Occidental. Su lógica fue determinada por el agua, y así la tierra fue comprendida como los terrenos más allá del enorme mar de agua dulce surcados. ${ }^{3}$

Todo miembro de una tripulación a bordo de un buque en navegación costera sabe que debe tener datos precisos de profundidad y tipo de lecho en los lugares en los que se mueve. Esto implica que además de tomar decisiones sobre el rumbo de la nave, debe definirla tomando datos del fondo de la cuenca. Esa información obsesivamente recopilada y registrada con claridad es la que ratifica o modifica las decisiones de la ruta.

En dos oportunidades, con cinco décadas de diferencia y registros cartográficos escasos e imprecisos, se decidió que un asentamiento en la margen sur del estuario del Río de la Plata estuviera en la misma porción de territorio con pretensión de continuidad en el tiempo. Es claro que la misma decisión tomada por dos personas diferentes estuvo asociada a lecturas interpretativas similares. Es interesante resaltar que ambos cumplían con un mismo contexto funcional (ser navegantes) y estuvieron condicionados al mismo tipo de información. Los datos a obtener desde un buque en un sitio relativamente desconocido pero cumpliendo con iguales rutinas, pueden terminar restringiendo de manera similar las opciones tomadas.

Los bajeles del siglo XVI tenían centralmente una dependencia. Su sistema de propulsión. La fuerza eólica, los buenos vientos, determinaban la posibilidad de viajar o no. Los lugares de buenos vientos eran descriptos como lugares excelentes para llegar y partir, pero además como lugares para estar. Es evidente que el estar implicaba poder acceder y poder partir. Ya para el proceso de mundialización del siglo XVI, viajar era condición obligatoria para poder habitar. El aislamiento de siglos anteriores en cualquier punto del mundo, ya no era posible. La posición de un nuevo asentamiento estuvo entonces valorada entre otras razones por su accesibilidad internacional, donde la internacionalidad a gran escala solo era posible a través de los océanos y por tanto bajo la necesidad del uso de buques capaces de viajar largas distancias.

Aire y agua son entonces elementos clave para un miembro de una tripulación pero a la vez lo son para una determinada posición en tierra firme, y no tanto como recursos directos sino como piezas fundamentales para garantizar su accesibilidad y por tanto su supervivencia. Son temas evidentes para que un navegante valore un territorio. Para que decida donde desembarcar y afincar.

Las condiciones topográficas de las tierras planas bajas del estuario del Río de La Plata no presentan una gran variedad de opciones para encontrar alguna cualidad distintiva que defina la posición de un futuro asentamiento permanente. Toda la región, sin embargo tiene buenos vientos. Con sólo ubicar algún punto alto, a salvo de las mareas y de los momentos nocivos de vientos exagerados (la sudestada) se logran datos favorables para hacer pie en tierra. Si las cuestiones en suelo firme pueden verse con tal facilidad, el problema se complica en el medio que asegura y condiciona el acceso, es decir en el espejo de agua. Pero en una topografía de pendientes extremadamente suaves, todo se define conociendo los rasgos de la geometría del lecho fluvial.

Un navegante en su derrota cercana a la costa, especialmente cuida los datos que mide del lecho. Los navegantes que llegaron al estuario y colocaron a la ciudad en su posición, midieron con mucho cuidado y atención las profundidades o mejor dicho las diferencias en las alturas de los accidentes topográficos subacuáticos. Esa geometría es fundamental siempre. Pero lo es más aún cuando el material principal 
del suelo es plástico. El lodo, aun con ciertas propiedades negativas, determinó en muchos casos la posibilidad de promover un asentamiento en diversas localizaciones en el mundo. Para Buenos Aires, tener un lecho de topografías suaves (como las terrestres) sin materiales duros, significó junto con los buenos vientos su posibilidad cierta de existir y persistir al menos durante 300 años.

Suelo blando (lodoso), vientos valiosos y topografía con pendientes suaves son entonces para el caso cualidades notoriamente favorables para su desarrollo. Ahora bien, estas cualidades no necesariamente son simples y positivas. Simultáneamente arribar a Buenos Aires implicaba la posibilidad de desembarcar pero también de encallar. La condición dinámica del lodo en el lecho, implicó la necesidad de un conocimiento de la topografía. De no tenerlo, arribar podía ser una tarea imposible. Así es como la ciudad nunca pudo ser asediada militarmente con fuerzas de acción naval. Las fuerzas militares que intentaron tomar la ciudad, debieron hacerlo por tierra, no desde el espejo fluvial. La defensa de la ciudad fue garantizada no por una población militar abundante o por infraestructura desarrollada para tal efecto. El territorio en su totalidad (acuático y terrestre) determinó esta característica absolutamente infrecuente. No existen otros ejemplos en América Latina que pudieran sobrevivir sin infraestructura militar que modificara el terreno.

Revisando las actividades comerciales, es inevitable volver a pensar en la posición de la ciudad en el estuario. Nuevamente, arribar y zarpar, plantean problemas de resultados diversos. El comercio fue posible siempre, de cara a las condiciones del territorio. Vientos favorables y un fondeadero frente al asentamiento de la población. La ausencia de infraestructura (muelles, espigones, diques de atraque) fue motivo para los reclamos de los comerciantes tanto en época temprana tanto como en momentos virreinales, así como en momentos de la independencia. Siempre la cuestión fue la necesidad de los elementos que favorecieran el movimiento de carga y descarga de mercaderías y personas. No tener muelle siempre favoreció que todo buque fondeara libremente, y por tanto, el comercio legal o ilegal fue parte cotidiana de las actividades dela ciudad, aún con la dificultad de su control estatal. De hecho, con tanto tiempo de “restricción” real al comercio libre, la ciudad vivió de esa actividad.

El nombre del río da cuenta de su valor como pieza de un conjunto de lugares conectados. En el Río de La Plata, no hay tal mineral. Es una clara nominación que resulta de referirse a un destino posible en caso de navegarse en su totalidad. El ancho y corto río es una parte de la ruta posible para llegar a los territorios de las minas de Norte. Ni siquiera es un río por el cual saliera un gran volumen del metal en barcos hacia Europa. Las rutas más frecuentes fueron otras. Sin embargo su nombre define una cualidad relativa a su potencial. La evidente característica de comunicar inherente a todo río, así como la específica de conectar un territorio en especial con otro. La única ruta fluvial al territorio minero, es por el Río de La Plata. La ciudad debe a su localización el éxito de haber estado comunicada con el mundo, aún en el extremo y zona marginal del Imperio. ${ }^{4}$

En las dos acciones fundacionales (1536 y 1580), Buenos Aires fue situada con cierta aproximación frente al mismo sector costero del Río de la Plata. Más allá del sitio terrestre exacto, es claro que lo determinante en un territorio como el del río es el grado de accesibilidad acuática y terrestre por medio de naves. No cabe duda que en ambas acciones los conocimientos científicos y empíricos de los navegantes resolvieron con gran pericia esta cuestión. Sólo buenos navegantes pudieron resolver navegar con éxito ante un tema complejo como es la topografía subacuática del estuario y su dinámica tanto hídrica como de suelos, vientos y sedimentación. Son numerosos los relatos de viajeros que exponen las peripecias de desembarcar en el puerto de Buenos Aires. Entre ellos podemos nombrar a Brackenbridge 1819, Andrews 1827, Haigh 1831, Isabelle 1835, Robertson \& Robertson 1843, Mac Cann 1853, Wilde 1881. 
El frente costero seleccionado responde a una geoforma muy clara en la fase terrestre. Un conjunto de barrancas suaves y de poca altura distribuidas en una línea casi recta orientada Norte Sur. En relación directa con ella se localiza bajo el agua una doble situación: por un lado una extensión relativamente plana con una profundidad original promedio de 2 a 3 metros y por otro un sistema de lomadas subacuáticas o bancos que dificultaban la navegación. La combinación de zonas planas y bancos, definieron los lugares de accesibilidad a la costa y por ende a las márgenes de la ciudad.

Los suelos planos fueron con el uso convertidos en el fondeadero, y a la vez definieron los puntos de acceso al asentamiento en tierra. El desconocimiento de este sistema terrestre y subacuático estableció una lógica de supervivencia muy valiosa para la continuidad del asentamiento.

\section{El paisaje a través de las imágenes de la época}

Pensando a la ciudad como resultante de la interacción entre hombre y naturaleza, desde lo inseparable de esa relación, desde lo necesario de todos los componentes armando un conjunto, Buenos Aires no parece haber sido una ciudad que desconociera su posición. Frente a lo dicho, es posible de afirmar que la conciencia de la ciudad solo fue posible por la pertinencia de la relación, por la potencia lograda gracias a una sutil y cuidada dependencia del territorio y sus cualidades. En todo caso, se presenta como una resultante con rasgos fuertemente identitarios.

El territorio solo cobró sentido en el conjunto a partir de la acción del hombre y gracias a la existencia de una herramienta, un objeto, los edificios móviles, la arquitectura naval. Sin los barcos y su recurrente presencia en el estuario, Buenos Aires no hubiera sido posible.

Rara vez el estuario fue navegado por flotas comerciales organizadas desde las empresas comerciales de las coronas europeas. Buenos Aires no participó del sistema de Galeones de España, como si sucedería en el Caribe y Filipinas o Perú. Tampoco fue común el ingreso de escuadras militares. En la mayoría de los casos, las naves militares ingresaron al estuario tardíamente en el S. XVIII o principios del S. XIX por mencionar solo momentos de la época colonial. Las naves que hicieron posible la existencia de la ciudad eran privadas, pequeñas y dedicadas casi exclusivamente al comercio. Los armadores de las mismas generalmente fueron los responsables de abastecer con lo necesario a la ciudad. Esos barcos tenían la capacidad de navegar estas aguas, y de cumplir con el tipo de tarea que fuera necesario. Hoy día se los conoce como "los multipropósito".

Si tomamos solo algunas imágenes de lo que fuera la ciudad de Buenos Aires y su entorno costero visto por distintos artistas y viajeros en el transcurso de los años, podríamos hacer una serie de observaciones en relación a las características que le dieron su identidad a la ciudad.

Las imágenes seleccionadas responden al período previo a la construcción de grandes obras de infraestructura que modificarían totalmente la relación de la ciudad en su fase terrestre con la porción acuática (superficial y subacuática). Ocupan cronológicamente el espacio que va desde la designación de la ciudad como cabecera del Virreinato del Río de la Plata y la primera década posterior a la declaración de la Independencia (aproximadamente 50 años en total). Son los años del final de una ciudad que pudo funcionar y desarrollarse con el uso de un recurso natural como el río, sin tener que invertir cifras ni esfuerzos notables para potenciar su localización estratégica tanto para el comercio como para la defensa. 
Teoría y Práctica de la Arqueología Histórica Latinoamericana | Año VIII. Vol. 8 | 2019

ISSN en línea: 2591-2801 | ISSN versión impresa: 2250-866X

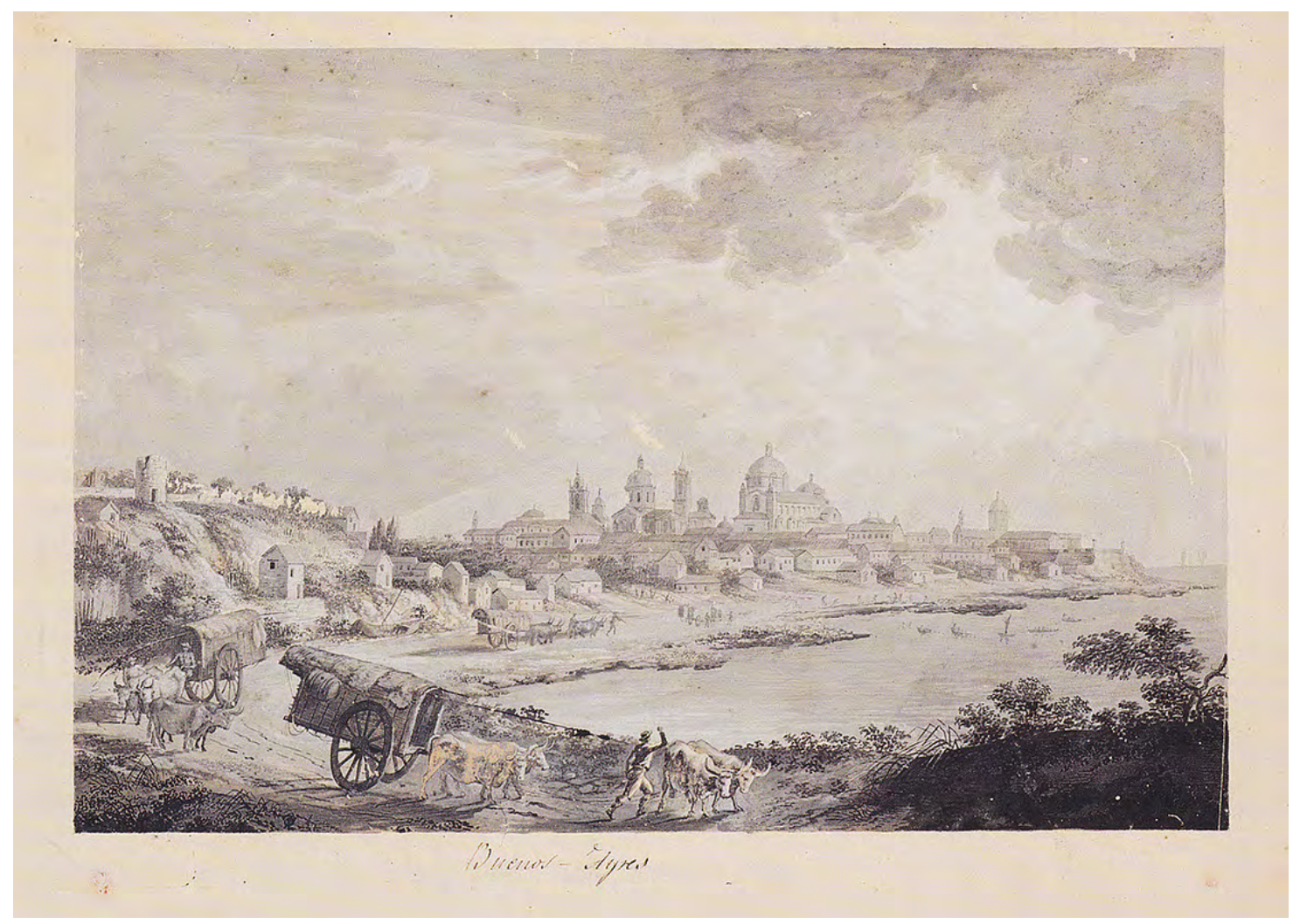

Fernando Brambila 1789. Museo Naval de Madrid

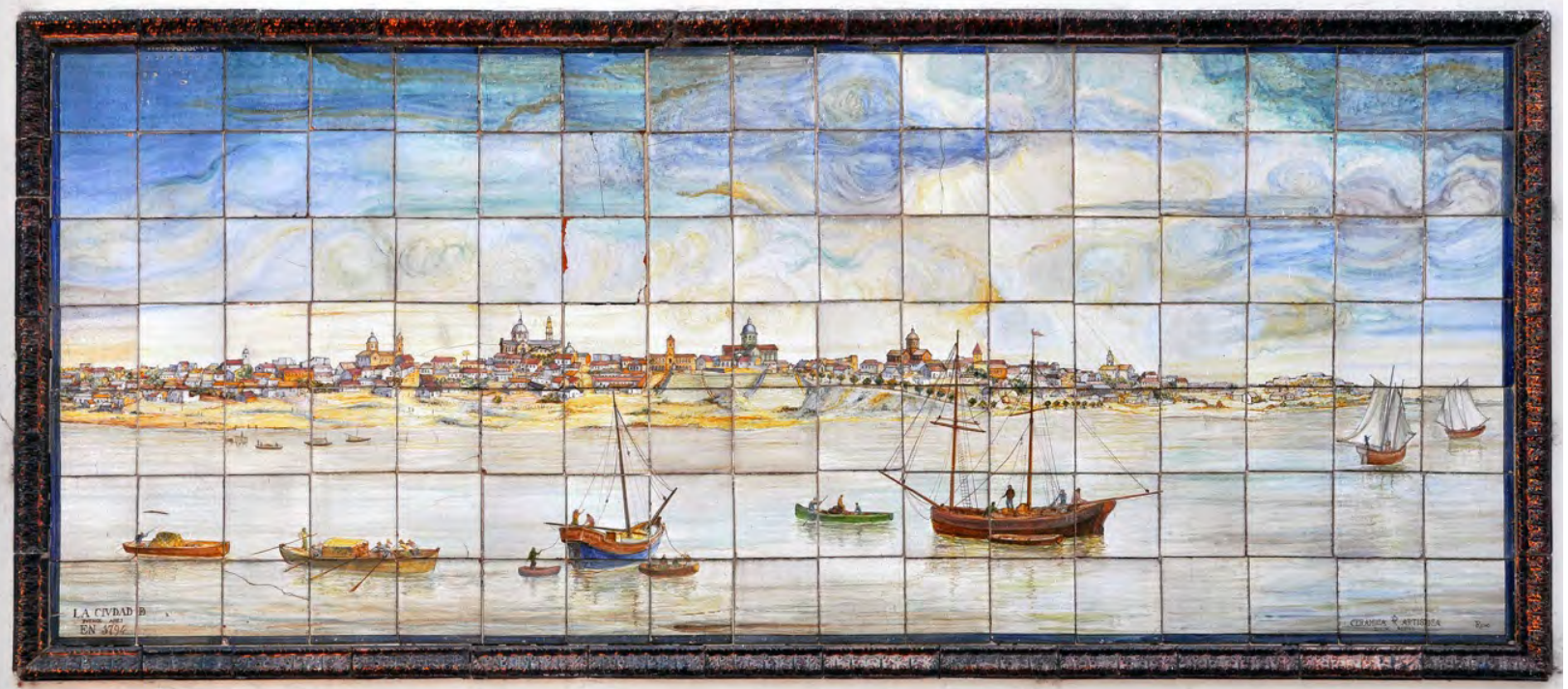

Mural de Azulejos 1794. Atrio de la Iglesia Nuestra Señora del Pilar, Buenos Aires. Foto de Javier García Cano. 
Teoría y Práctica de la Arqueología Histórica Latinoamericana | Año VIII. Vol. 8 | 2019

ISSN en línea: 2591-2801 | ISSN versión impresa: 2250-866X

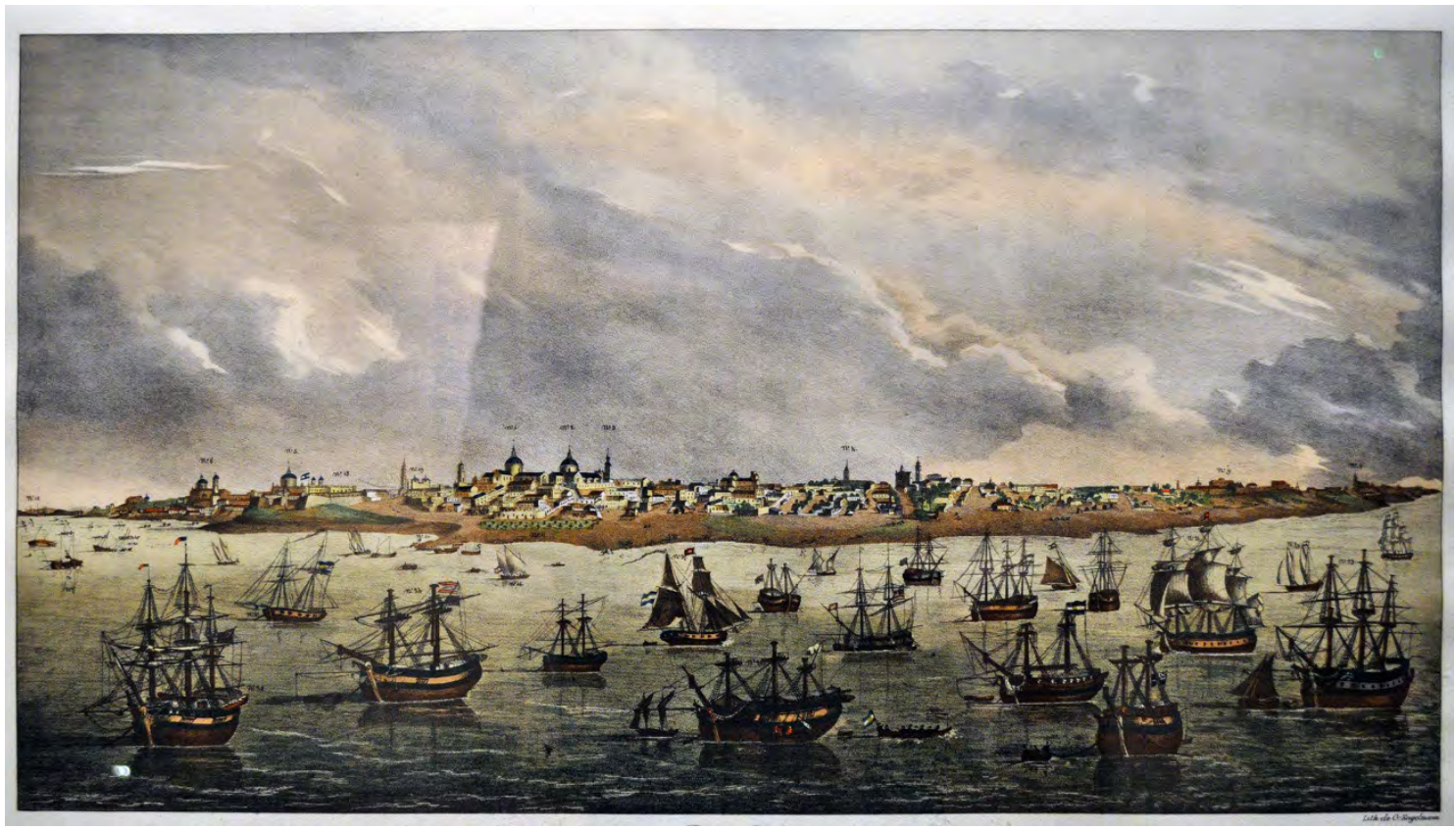

Villa y Rada de Buenos Aires 1823. Editor del al Librería de la Capilla del Puerto. Museo de Casa Rosada. Foto de Javier García Cano.

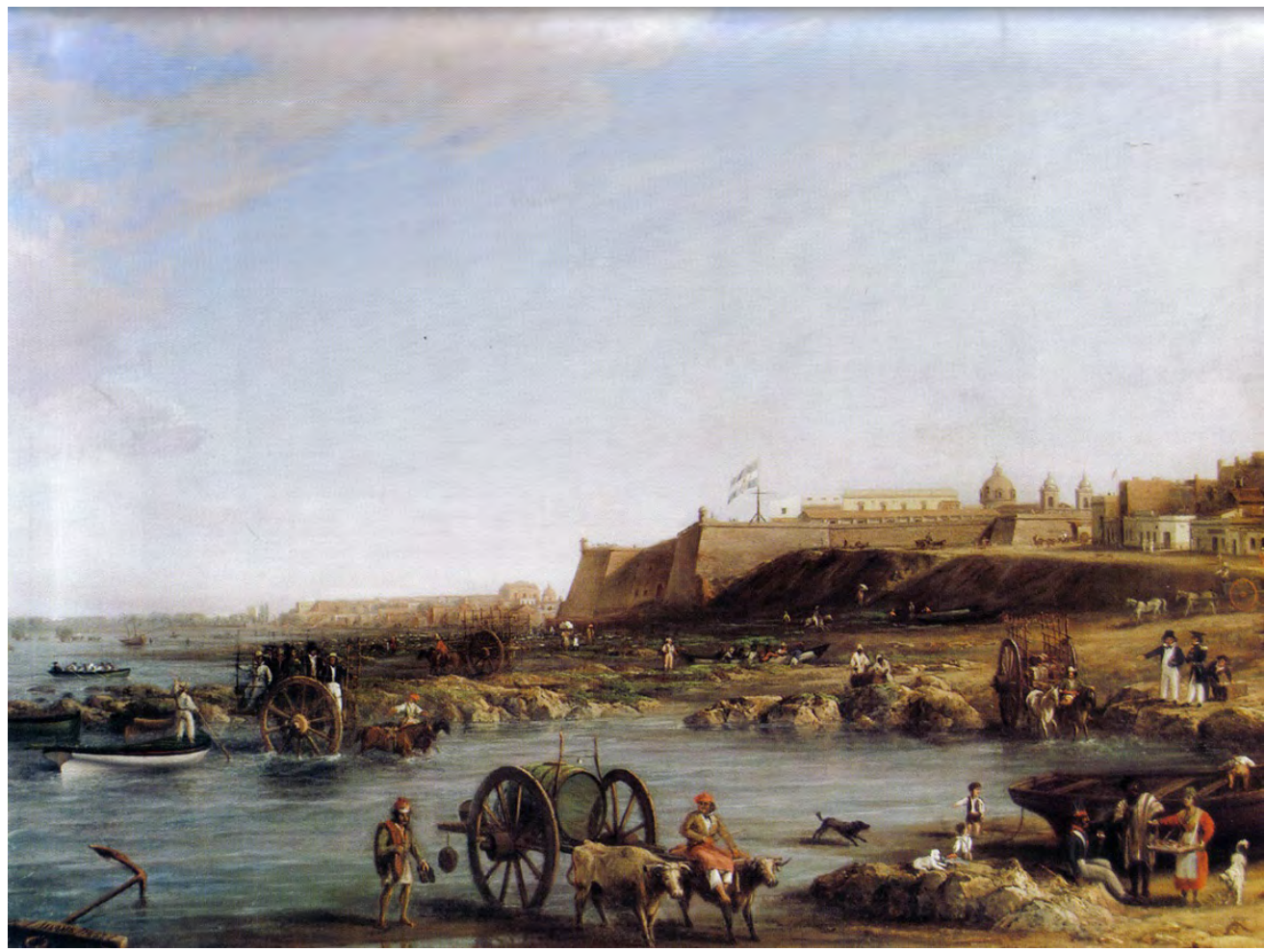

Richard Adams 1825. Centro de Arqueología Urbana. IAA FADU UBA. 

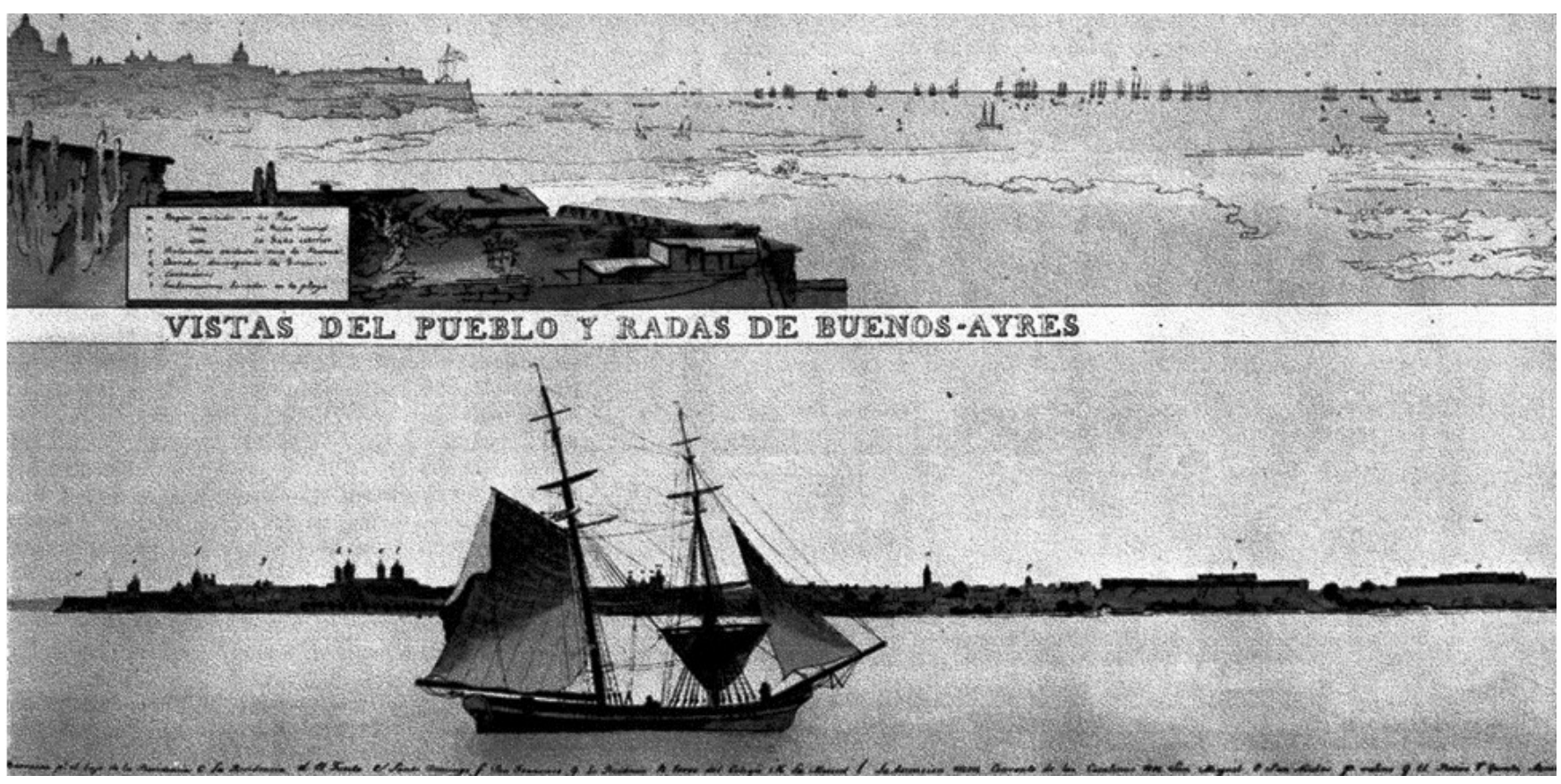

Vistas del pueblo y radas de Buenos Ayres, tomada de la acuarela realizada en Buenos Aires en 1813 por C.H. Pellegrini

De modo de revisar con parámetros igualitarios las imágenes seleccionadas, desarrollamos una serie de temas que nos han servido de guía:

\section{Sustentabilidad y Defensa:}

Debe considerarse un atributo único la posición estratégica del asentamiento respecto del río. Gracias al sistema descripto, la compleja geometría del lecho permitió que Buenos Aires fuera militarmente sustentable casi sin inversiones de gran escala, cosa que en general no sucedió en estos términos en el resto del Imperio Español. Durante el siglo XVIII, fueron varias las oportunidades en las que las administraciones locales reclamaron inversiones a la Corona, y las mismas fueron negadas.

Durante la gestión de Manuel Belgrano en el Consulado de Buenos Aires se desarrolló un expediente que tenía por objeto lograr inversiones de la Corona para construir infraestructura que facilitara el acceso de buques a la costa. Dicho expediente no tuvo éxito en el S.XVIII, por la sistemática renuencia de España.

Más allá de la justicia o no de las respuestas de la península, las condiciones topográficas del lecho del río frente a la ciudad sirvieron con efectividad de argumento para no invertir. Las acciones bélicas británicas de principios del S. XIX lo corroboran. Para poder llegar a Buenos Aires, desembarcaron lejos de la ciudad, en territorios en los cuales los buques pudieran tener mejor accesibilidad a la costa sin ser objeto de defensa directa.

En estos términos es que también resulta interesante ver que la eficiencia de la localización del asentamiento aseguró una defensa muy larga en el tiempo a muy bajo costo aún con los cambios en la tecnología bélica en especial las mejoras en la artillería de los S. XVII y XVIII. La mayoría de las ciudades del Imperio en América fueron objeto de actualización en sus defensas, inclusive a fines del XVII y durante el XVIII de acuerdo a los desarrollos de Vauban. Buenos Aires no tuvo esa necesidad. 
La distancia de tiro desde un buque hacia la costa siempre fue insuficiente como para poder alcanzar el objetivo. Esto justificó que no fuera necesario invertir en infraestructura militar de gran escala. Esa distancia estuvo definida por la topografía subacuática y su relación con la línea de costa.

\section{Topografía subacuática:}

La geometría del lecho (combinación de sectores planos y sectores de lomadas) y especialmente la distribución de sus componentes no sólo facilitaron la defensa militar. También permitieron que aún con la queja permanente de la población, sin inversiones específicas, los buques pudieran fondear eficientemente.

El banco paralelo al frente costero coincidente con la porción central y más densamente ocupada en forma exclusiva hasta casi la totalidad del S XIX, es la pieza clave de todo el sistema. Los buques no podían acercarse a la ciudad sin tener un buen conocimiento del mismo. A su vez, por fuera del banco y especialmente en el sector Norte, los buques podían fondear con tranquilidad respecto a la profundidad. Este dato esta en relación a una profundidad promedio estable aun con los cambios sistemáticos resultantes de la acción de las mareas (hay que recordar que el Río de la Plata tiene comportamiento de régimen marítimo), y solo sometido a problemas con bajantes muy extraordinarias o situaciones posteriores a grandes tormentas (dos o tres por siglo). Las bajantes extraordinarias provocaron retiradas del agua de hasta medio kilómetro de la línea de costa normal.

La iconografía de los siglos XVII a XIX da cuenta del uso que los buques hacían del río, y documenta la inevitable situación de fondear de manera extensiva por fuera del banco. Es también cierto que en el caso de embarcaciones de menor calado, el canal paralelo a la costa era usado para ingresar al Riachuelo, y en muchos casos para echar anclas o para tirar a tierra o navegar en sirga riachuelo arriba. Pero esta forma de uso del sistema siempre estuvo muy restringida a condiciones especiales y momentos en los que el clima y la dinámica hídrica lo permitieran.

\section{Fondeadero:}

Dadas las características del lugar descriptas es sencillo comprender que la zona de uso para tener y acceder a las embarcaciones frente a la ciudad tradicionalmente llamado puerto, en la ciudad de Buenos Aires fue realmente hasta el S XIX un área de calado relativamente parejo y sin infraestructura alguna. Estas son las cualidades que definen a un fondeadero. Es un área con pocos atributos como interface de las actividades náuticas y o navales

Todos los fondeaderos son esencialmente un lugar con buenas características naturales básicas, pero son además lugares que no completan las necesidades de las actividades en el largo plazo, si es que se considera algún tipo de desarrollo y crecimiento de las mismas.

Los fondeaderos suelen tener deficiencias en temas como protección de los buques respecto de las inclemencias del clima o las facilidades para embarcar o desembarcar sin tener que depender de embarcaciones secundarias. Son lugares que podrían cumplir con todos los requerimientos en tanto y en cuanto se los dotara de la infraestructura que complementara sus deficiencias.

Buenos Aires en su sector anterior al frente costero fue un fondeadero por las ya descriptas cualidades formales de la topografía subacuática. No cumplió con más necesidades que la de poder tener calado cercano a la costa donde con poca profundidad echar anclas y asegurar cierta fijación de la posición del buque. Fue además un fondeadero totalmente desprotegido de tormentas, marejadas y vientos importan- 
tes. Estuvo seriamente afectado por las grandes bajantes, y especialmente fue objeto de críticas por no poder asegurar las maniobras de embarcar y desembarcar personas (pasajeros y tripulantes) tanto como mercaderías. Sus únicos atributos geográficos estaban concentrados en su topografía subacuática plana y la existencia del banco difícil de asociar a cualquier referencia en la costa. De hecho la ventaja de una extensión importante con profundidades similares es que tenía mucho lugar donde se podía fondear con cierta libertad de ubicación.

La costa tampoco ofrecía protección alguna, especialmente de vientos terrestres. Esto es entonces que fue un fondeadero sólo valioso por lo que significaba el lecho del río.

La falta de mejores condiciones fue lo que motivó a que el Consulado de Buenos Aires se convirtiera en el principal promotor de obras de infraestructura que resolvieran los problemas. Las mayores preocupaciones estaban centradas en el manejo de la carga. Las dificultades de trasvase entre embarcaciones fondeadas y otras menores, o entre las naves y carretones de tiro, con la consecuente inseguridad resultante fueron la base de todas las argumentaciones negativas del fondeadero. Lo propio se aplicaba al transporte de pasajeros desde y hacia la costa. Los intentos y proyectos sólo procuraban resolver lo dicho por medio de la construcción de un muelle perpendicular al desarrollo del frente costero y con la idea de localizarlo tan cercano como se pudiera a la zona de mayor frecuencia de uso del fondeadero, es decir en el sector norte de la ciudad original. Este muelle proyectado no tenía por objeto el atraque de buques por períodos largos, solo fue concebido para resolver las actividades de carga y descarga, embarco y desembarco, y por tanto amarre breve y temporal.

Esto significa que Buenos Aires pasaría (y así fue en los inicios del S XIX) de ser un fondeadero muy sencillo a un puerto muy básico, o tal vez mejor dicho un fondeadero con un muelle muy sencillo.

\section{Puerto:}

Todas las condiciones de un puerto, atendiendo a los problemas tanto de maniobras de acceso como de protección de los buques sólo se resolvieron a finales del S XIX. Dadas las cualidades tan básicas de Buenos Aires, fue inevitable realizar grandes obras para poder convertir el fondeadero en un puerto.

La mera idea de uno o varios muelles resolvió lo básico de las maniobras, pero no los enormes problemas de la seguridad de buques y tripulaciones ante el clima. Aun así, es decir siendo muy tardío el momento en el que la ciudad adquiere su condición integral de puerto, desde muy temprano fue nominada como tal. En realidad la cuestión es que la nominación de puerto estuvo más asociada a la dependencia de la ciudad respecto de las actividades antrópicas en el estuario y a que fue fundada desde los barcos y no a la precisión del significado de la palabra. El uso técnicamente definido de fondear, no se lo entendió como la función que definía el lugar. Por lo tanto el fondeadero fue puerto, aun sin serlo.

Nada de esto pretende afirmar que un puerto solo es tal si tiene una infraestructura que permita asignarle tal condición. Solo es que Buenos Aires accedió a la categoría de puerto muy tardíamente, a pesar que desde muy temprano y aun sin cumplir con todas las condiciones para serlo se la llamó “puerto”.

\section{Infraestructura:}

La tardía condición de puerto de Buenos Aires resulta de haber desarrollado la infraestructura necesaria para completar la cantidad de cualidades mínimas que permitieran su cambio desde el original fondeadero. Sin embargo de alguna manera el deseo inicial de ser puerto, aunque técnicamente no lo fuera, planteó la base de a pesar de las dificultades y carencias fuera logrado. Mucho tiempo pasó desde 
la fundación de la ciudad hasta que el gentilicio coincidiera con la categoría funcional del lugar. Es interesante resaltar que la ausencia de infraestructura también fue posible por las cualidades naturales para que con lo mínimo se resolviera la cuestión básica de sustentabilidad del asentamiento por la eficiencia del fondeadero. En ese sentido hay que recordar que el lugar de fondear fue valioso por la existencia de los sectores de topografía subacuática que permitieron la defensa natural de la ciudad. Tal que, hablar de fondeadero en Buenos Aires debe considerar el sistema complejo de sectores profundidades similares y continúas tanto como los del banco y los pozos, ofreciendo entonces las opciones para que a pesar de las falencias en otras necesidades, finalmente garantizara su uso por varios siglos.

En relación a la imagen de Brambilia, la misma fue una de las tantas producidas en el marco de la Expedición Científica que circunnavegó el mundo al mando de Alejandro Malaspina. ${ }^{5}$ Tiene como punto focal la porción terrestre de la ciudad de Buenos Aires, con la posición del observador en la zona marginal externa de la misma y con una orientación Sur Norte sobre la ribera del río. Es de las pocas imágenes producidas por la expedición que no se realiza desde una nave y con su autor en tierra. Con claridad se distingue cómo la interface intermareal no está ocupada por infraestructura o arquitectura alguna. Dada la escasa distancia entre la línea de agua y la base de las barrancas (las zonas altas de la topografía ocupadas por edificios) podría asumirse que el registro gráfico da cuenta del momento de una marea alta. La porción costera no ocupada se presenta como un territorio de uso público para el transporte. De hecho los motivos del primer plano lo conforman un par de unidades para el transporte con propulsión a sangre.

La geomorfología del suelo da cuenta de la conformación (topográfica y de componentes materiales) del lecho del río, ahora descubierto y a simple vista. La irregularidad de su perfil es resultante de las diferentes durezas y mezclas de componentes materiales (arcilla, conchillas, toscas, depósitos biológicos, etc) y es muy claramente registrado. La continuidad del perfil de las cotas terrestres y subacuáticas es sugerida particularmente en el detalle de la forma de definir el límite conocido como la línea de agua (o de tierra-agua). No existe presencia alguna de materiales duros, los detalles de los grafismos utilizados sugieren especialmente materiales blandos y una naturaleza plástica del suelo.

Si bien en esta imagen el espacio público acuático de la ciudad tiene una jerarquía menor en términos cuantitativos, se presenta como una totalidad junto con la porción terrestre.

\section{Barcos, la identidad de Buenos Aires}

Al terminar el período Medieval Europeo, los buques multipropósito eran aquellos que pensados básicamente según los lugares donde navegar, podían transportar mercadería, personas o artillados hacer la guerra. Estos barcos del común, los menos específicos en términos de funcionalidad, los más construidos, fueron los que llegaron a Buenos Aires desde las primeras navegaciones al extremo sur del continente. Los multipropósito del siglo XVI, resultaron aptos para cruzar el océano, y gracias navegantes con habilidades notables, fueron las plataformas que permitieron estudiar el estuario y definir la existencia de la ciudad.

Sin un sistema de abastecimiento de bienes de consumo y materias primas organizado por empresas del estado (como sí sucedió en las zonas centrales del Imperio), la ciudad existió a partir de las actividades de las pequeñas empresas de individuos europeos que hicieron llegar todos los elementos necesarios. El sistema en realidad fue organizado por emprendedores privados, dueños de barcos medianos o pequeños. La eficiencia de esas naves para cruzar el océano fue la clave para la permanencia de la ciudad. Estos buques de no más de 30 a 35 metros de eslora, que podían tener hasta 100 hombres de tripulación y una sola cubierta como protección en la ruta, son los multipropósito ya mencionados. 
Sus cualidades marineras y su robustez favorecieron la durabilidad y el mantenimiento de una ruta difícil y no atractiva para los grandes comerciantes europeos. Estos barcos fueron la pieza de sostén de la cotidianeidad de poblaciones con poca posibilidad de crecimiento. En particular aquellos que sostuvieron a Buenos Aires, llegaron allí conscientes de arribar al último puerto de recalada aún hasta finales del S XVIII. Es interesante ver que estas regiones sin interés comercial de gran escala, fue viable por los resultados económicos de armadores que podían resolver la pequeña escala del comercio de alto riesgo. Poca población, con poco poder adquisitivo y casi sin producción local exportable, se sumó a los temas de navegaciones larguísimas (con las distancias navales más largas del mundo), y configuraron altos niveles de riesgo comercial.

Fragilidad es una palabra que da cuenta de la situación de Buenos Aires a lo largo de no menos de 300 años. Robustez es la característica constructiva de los multipropósito que aseguraron la supervivencia del asentamiento. La relación entre el río y la ciudad, claramente sostenida y larga, solo se explica por la posibilidad de los barcos que asociados a una posición muy especial en el territorio mantuvieron el tráfico y el vínculo. La robustez y capacidad marinera no hubieran sido útiles sin la posibilidad de acercarse exitosamente y sin inversión económica en infraestructura a una costa tan peculiar como la rioplatense sur. Sin fragilidad, la relación entre Buenos Aires y el río hubiera sido abastecida por buques de otro porte o con otros objetivos. La mayoría de las ciudades costeras americanas del Imperio Español desarrollaron su existencia gracias a las Flotas de Galeones o a la presencia de las naves militares de la Corona. En todos esos casos, el valor económico de las inversiones siempre fue muy considerable. La supervivencia no estaba puesta en duda, estaba fomentada y promovida por la acción del Estado.

"Mucho antes de realizar mejoras de importancia en su puerto, Buenos Aires era el mercado para el comercio exterior en el estuario del Plata, al mismo tiempo que la ciudad crecía acorde con la expansión del comercio. El ascenso de Buenos Aires hacia la dominación de la actividad naval se vio beneficiada por la construcción de obras para la renovación de su puerto llevadas a cabo después de 1860." ( Kroeber 1967:64)

En Buenos Aires, la notoria claridad del saber de los navegantes y las cualidades sobresalientes de los barcos, fueron las bases para que un enclave existiera a pesar de todo y finalmente se expandiera más allá de lo que ninguno de sus fundadores jamás imaginara.

Existió una activa circulación comercial en lo que Jumar (2000) señala como un sistema regional en el Río de la Plata en donde circulaba la mercancía entre Buenos Aires, Uruguay, Chile y el Alto Perú.

Los restos del "pecio" de Zencity formaron parte de ese sistema mercante que acompañó el crecimiento y afianzamiento de la ciudad de Buenos Aires, especialmente desde principios del siglo XVIII. 


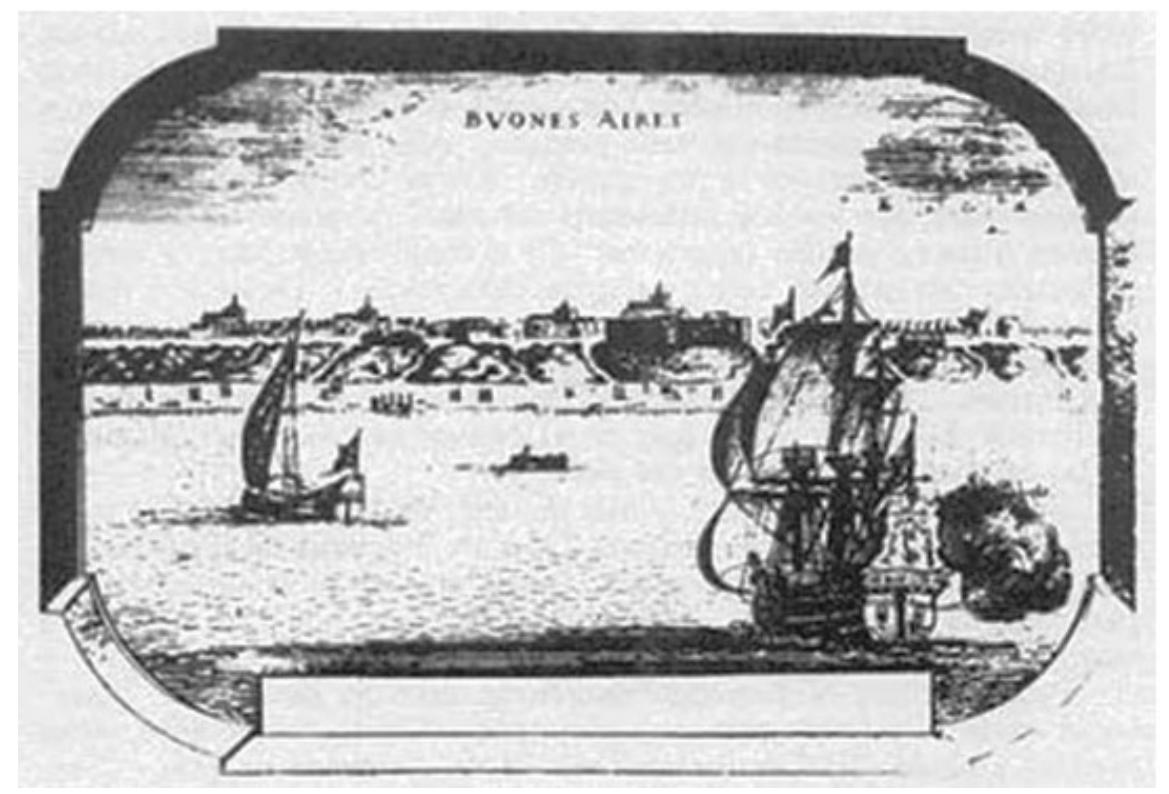

Anónimo, circa 1650

\section{Notas}

12 El principal objetivo de estas tareas de relleno siempre fue ganar terreno a las aguas del estuario, como resultado de una política de expansión. Se estimó que durante los últimos 162 años se produjo un relleno artificial de 12,67 hectáreas por año, con una progradación costera variable entre los 400 y 1000 metros. (Marcomini y López 2004: 261)

${ }^{3}$ Nuestra Señora del Buen Aire, Nuestra Señora del Buen Ayre, Virgen del Buenaire o Virgen del Bonaire es una de las advocaciones marianas de la Virgen María. Iconográficamente representa a la Virgen de la Candelaria. Fue considerada por los navegantes españoles como la patrona de los navegantes y su nombre dio origen al de la ciudad de Buenos Aires, siendo Pedro de Mendoza devoto de ésta virgen considerada como milagrosa entre los navegantes.

4 "Una de las razones que impulsaron a la Corona a propiciar la expedición de Mendoza fue la posición estratégica del territorio como flanco protector del Perú y vía de acceso a Potosí, que cobraba sentido ante el peligro del asentamiento portugués y luego ante las posibles invasiones de ingleses y holandeses. Es comprensible que a la par del auge minero de Potosí y la capital importancia del Perú dentro del imperio, estas razones estratégicas cobraran una relevancia cada vez mayor.” (Assadourian et al, 1985: 25)

${ }^{5}$ La expedición de Alejandro Malaspina y José de Bustamante y Guerra visitó los territorios españoles de ultramar entre 1789 y 1794 a bordo de las corbetas “Atrevida” y “Descubierta”.

\section{Referencias bibliográficas}

ARZE, M.E. (1981). Comercio exterior del Río de la Plata, 1816-1880. En Revista Nacional de Cultura. Año 3, Nro. 10.Pp.: 65 a 104.

ASSADOURIAN, C. S. B., CHIARAMONTE, G., y ASSADOURIAN, J. C. S. (1986). Argentina: de 
la conquista a la independencia. Tomo 2. Buenos Aires: Paidós.

AUSTRAL, A.; GARCÍA CANO, J. Y LUQUI LAGLEYZE, J. (1998). Arqueología Portuaria: la ciudad de Buenos Aires a través de sus restos bajo el agua. Actas de las Primeras Jornadas de Arqueología Histórica de la Provincia y Ciudad Buenos Aires. Universidad Nacional de Quilmes. Municipalidad de Quilmes. Ms.

AZARA, F.[1794] (1847). Descripción e historia del Paraguay y del Río de la Plata. Madrid: Imprenta de Sanchiz,

BROWN, A.G. (1997). Alluvial Geoarchaeology. Floodplain Archaeology and Environmental Change. Cambridge Manuals in Archaeology. Cambridge: Cambridge University Press.

CEREZO MARTÍNEZ, R. (1987). La Expedición Malaspina 1789-1794. Ministerio de Defensa. Museo Naval de Madrid. Lunwerg Editores.

CIARLO, N. (2008). La arqueología subacuática en Argentina. Reseña histórica de los antecedentes, desarrollo de la especialidad y estado actual de las investigaciones. Revista de Arqueología Americana. 26: 41-70.

GUAGLIARDO, J.P. (2007). El infierno de los marinos. Distribuciones de naufragios en el Río de la Plata, siglos XVI-XX. En Cuadernos del Instituto Nacional de Antropología y Pensamiento Latinoamericano, $\mathrm{N}^{\circ}$ 21, 2006/2007.

FERNÁNDEZ J. C. (1999). Juntando los pedazos: Primeros hallazgos arqueológicos subacuáticos de la Argentina (1887-1890). La Plata: Actas del XII Congreso Nacional de Arqueología Argentina, t. I: 427-431.

FUNARI, P. P. (2015). Historia Comparada en Iberoamérica: Ciudades Españolas y Portuguesas en el Nuevo Mundo. En Revista de História Comparada, 9 (1), 69-87.

HOLOCWAN, P. T.1995. Evolución y acción antrópica en el sector costero de la ciudad de Buenos Aires y sectores aledaños. Tesis de Licenciatura. FCEyN. UBA.

JUMAR, F. A. (2000). Le commerce atlantique au Río de la Plata, 1680-1778 (Doctoral dissertation, EHESS).

KROEBER, C. (1967). La navegación de los ríos en la historia argentina. Buenos Aires: Paidos.

MADERO, G. (1955). Historia del puerto de Buenos Aires. Buenos Aires: Emecé Editores.

MARCOMINI, S. y R. Álvaro López. Historia de la costa de Buenos Aires. Buenos Sires: Departamento de Geología, Facultad de Ciencias Exactas y naturales. Universifad de Buenos Aires.

PEREYRA, F. (2004). Geología urbana del área metropolitana bonaerense y su influencia en la problemática ambiental. En Revista de la Asociación Geológica Argentina, 59 (3): 394-410.

RAMOS, M. (1999). Algo más que arqueología de sitios históricos: una opinión. En Anuario de la Universidad Internacional SEK, (5), 61-76. 
SHANKS, M.,\& TILLEY,C.Y. (1992). Re-constructing archaeology: theory and practice. Psychology Press.

VALENTINI, M. et.al.; compilado por Mónica Valentini y Javier García Cano. (2012) a. Un mercante español en el puerto de Buenos Aires: historias y hallazgos de Puerto Madero. Buenos Aires: Dirección General Patrimonio e Instituto Histórico.

VALENTINI, M. et al. (2012 b). Arqueología de un barco en Buenos Aires. En Perspectivas de la educación intercultural desde la Antropología y la Arqueología. Buenos Aires: Centro de Investigaciones Precolombinas. Instituto Superior del Profesorado Dr. J.V. González. Pp.: .31 a 40.

Recibido: 8 de junio de 2019

Aceptado: 20 de septiembre de 2019 